\title{
História e ficção no livro-reportagem Dossiê Brasília - os segredos dos presidentes, de Geneton Moraes Neto
}

\author{
Laísa Veroneze Bisol* \\ Denise Almeida Silva**
}

\begin{abstract}
Resumo: Este ensaio apresenta uma análise do livro Dossiê Brasília - Os segredos dos presidentes de Geneton Moraes Neto, que traz informações no formato perguntaresposta, dispondo, ainda, de textos complementares de apresentação dos políticos, a fim de fazer um resgate sobre diversos períodos da história dos bastidores do poder no Brasil. O objetivo do trabalho é verificar a existência do entrecruzamento entre a realidade e a ficção na obra e, para tanto, tomam-se como referência diversos estudiosos, sobretudo Paul Ricoeur. Este estudo centra-se na apresentação e entrevista constantes no capítulo dedicado ao ex-presidente Fernando Collor de Mello, o qual foi alvo de muitas polêmicas, especialmente em torno de sua gestão e afastamento do poder. A realização desta análise evidencia a presença da literatura em uma obra jornalística, corroborando a ideia de que a história e a fiç̧ão podem estar vinculadas em uma mesma obra.
\end{abstract}

Palavras-chave: Fiç̧ão. Livro-reportagem. Literatura. Geneton Moraes Neto.

O livro-reportagem Dossiê Brasília - Os segredos dos presidentes, de Geneton Moraes Neto, traz a série de entrevistas que quatro ex-presidentes do Brasil - José Sarney, Fernando Collor de Mello, Itamar Franco e Fernando Henrique Cardoso -, concederam ao programa Fantástico, exibido na Rede Globo em 2005. As entrevistas não são simplesmente transcritas na obra do jornalista: cada uma delas vem precedida por uma introdução que sugere o foco da próxima entrevista e gera expectativa quanto às perguntas e respostas que estão por vir, nas quais os expresidentes contam sobre alguns momentos que ocorreram durante seus mandatos, enfatizando os segredos que não poderiam ter sido revelados então. Nessa ocasião, contudo, revisitam a sua memória e contam ao repórter episódios sobre os quais até então haviam calado.

As produções jornalísticas, normalmente, primam pela busca da objetividade e imparcialidade. Contudo, sabe-se que o profissional do jornalismo não consegue atingir

* Mestranda em Letras, pela Universidade Regional Integrada do Alto Uruguai e das Missões - URI câmpus Frederico Westphalen. E-mail: laisavb@yahoo.com.br

** Doutora em Letras, e professora do Programa de Pós-Graduação em Letras da Universidade Regional Integrada do Alto Uruguai e das Missões - URI câmpus Frederico Westphalen. E-mail: dnsalmeidasilva@gmail.com 
estes objetivos em sua plenitude, considerando que precisa fazer escolhas na hora da escrita: desde o tema abordado, as informações e imagens priorizadas e o modo como cada acontecimento é descrito. O jornalista Ricardo Noblat discorreu sobre o assunto em sua famosa página na internet, "Blog do Noblat", em 2012, quando o portal comemorava seu oitavo aniversário. "Este é um dos mitos cultivados há mais de século: jornalista é imparcial. [...] Ninguém é imparcial. Porque você é obrigado a fazer escolhas a todo instante. E ao fazer toma partido".

O modo como o jornalista se apropria dos fatos para contá-los aos leitores, interpretando histórias, pode ser uma das características que tornam uma reportagem ou um livro-reportagem mais interessante do que uma matéria meramente informativa. Conforme Nilson Lage (2001), o jornalismo interpretativo consiste em informações em que se evidenciam consequências e implicações de fatos; nele o repórter apresenta os acontecimentos, ao mesmo tempo em que os avalia quanto a sua importância. E é isto o que acontece em Dossiê Brasília: Os Segredos dos Presidentes. Embora o jornalista não tenha modificado as respostas dos entrevistados, que seguem na íntegra, há sempre um texto de abertura, composto inclusive por metáforas, conforme o entendimento do autor, que visa tornar a obra ainda mais interessante.

De acordo com Edvaldo Pereira Lima (1995), um livro-reportagem difere das demais publicações porque se aprofunda em alguns aspectos: "quanto ao conteúdo, pois trata de assunto em que a veracidade é fundamental; quanto ao tratamento: linguagem, montagem e edição de texto e quanto à função: informar, orientar e explicar" (p. 30). Ainda que a busca ou a pretensão da veracidade seja um dos elementos essenciais de uma obra jornalística, sabemos que quando se trata de um livro-reportagem, a literariedade torna-se mais evidente na construção da narrativa, especialmente se considerarmos publicações cujo foco centra-se unicamente na informação. Isto não significa que o texto deixe de ser verdadeiro ou que retrate a realidade de forma fantasiosa. Contudo, a ficcionalidade aparece, mesmo que de forma sutil, nessas obras. Isto é perceptível já no texto de abertura do livro de Geneton Moraes Neto, capítulo que traz como título "O grande romance do poder".

O Brasil não é para amadores. Nunca foi. Aqui, o que aparece improvável acontece. O que é dado como certo não se confirma. O razoável é tido como loucura. O delírio vira fato: quem imaginaria que um presidente fosse erguer uma nova capital no centro do País, no meio do nada, depois de ouvir o palpite de um eleitor num comício? Pois ergueu. Chamava-se Juscelino Kubitschek de Oliveira, o JK. Quem sonharia que o presidente que se orgulhava de espargir próclises e mesóclises em frases rebuscadas fosse renunciar espetacularmente apenas sete meses depois de assumir o poder no rastro de uma votação consagradora? Pois renunciou. Chamava-se Jânio da Silva Quadros. (NETO, 2005, p. 6)

Embora os fatos apontados pelo jornalista sejam verídicos, não se pode deixar de notar a forma como a escrita se estabelece. A linguagem não se equipara à convencionalmente utilizada no jornalismo meramente informativo vem aparelhada com "adornos"; até mesmo a pontuação leva o leitor a fazer pausas que orientam para um dado sentido no texto. Mônica Fontana (2006), ao discorrer acerca desta aproximação entre literatura e jornalismo, explica que é a partir da revolução intelectual da Reforma, do Renascimento e do Iluminismo que se institui uma distinção 
mais acentuada entre fatos históricos e ficção, dado o desenvolvimento dos meios da impressão, com seu estímulo ao pensamento independente, livre da interferência das interpretações das autoridades eclesiásticas.

É possível, desse modo, ver tanto o jornalismo e sua investigação dos fatos como o romance moderno enquanto pura ficção como produtos do capitalismo emergente na sociedade e no estado burguês de então. Mesmo com uma ideologia regendo uma clara fronteira entre ficção e realidade, pode-se perceber que, de certa forma, ambos se misturam. O papel do romance tende a ser o de instruir pelo relato das experiências pessoais ou, mais tarde, pelo retrato da realidade social. O do jornalismo, promulgar mitos fundadores na formação das comunidades imaginadas pelas nações-estados. (FONTANA, 2006, p. 2)

É através desta representação daqueles que estiveram à frente do Brasil que o jornalista, além de apresentar fatos através das entrevistas, recobre sua narrativa de ficcionalidade. Paul Ricoeur, em seu livro Tempo e Narrativa, dedica um capítulo a esse entrecruzamento entre história e ficção. O estudioso afirma que existem trocas entre ambos: "a história e a ficção só concretizam suas respectivas intencionalidades tomando de empréstimo a intencionalidade da outra" (2010, p. 311). Ainda conforme Ricoeur, essa concretização só ocorre quando a história se serve da ficção para refigurar o tempo e, por sua vez, a ficção se utiliza da história com este mesmo objetivo. É este fenômeno que incide no livro-reportagem; no caso em análise, o autor recorre a figuras que fizeram parte da história do Brasil, inclusive dando rumos diferentes a elas, à sua maneira, a fim de contar estes episódios ao grande público, através de uma obra que, embora verídica, possui traços ficcionais, como tudo o que é escrito através da percepção de alguém.

Como objeto principal desta análise, selecionamos o capítulo do livro que diz respeito a Fernando Collor de Mello. Esta escolha deve-se ao fato de este expresidente ter sido alvo de muitas polêmicas que envolveram o seu mandato e processo de impeachment, o que resultou em uma história que está, até os dias de hoje, na memória não somente de Collor, mas também do país e, de modo especial, daqueles que vivenciaram aquele momento da política brasileira.

No capítulo dedicado à entrevista com Fernando Collor de Mello - que na ocasião era apenas empresário e encontrava-se afastado da política -, o entrecruzamento entre a história e a ficção ficam bem evidentes. É natural que os fatos históricos que envolveram o mandato do presidente estejam de acordo com a realidade; contudo, cabe ressaltar que as respostas aos questionamentos se originaram de perguntas elaboradas por um jornalista que esperava alguma resposta de seu entrevistado e este, por sua vez, recorreu a sua memória para poder responder aquilo que Ihe era questionado.

Nessa parte, o jornalista inicia justamente referindo-se à ficcionalidade:

Ficcionistas do Brasil, guardem as canetas, desconectem o computador, batam em retirada, entreguem os pontos: nenhum autor de folhetim teria imaginação suficiente para engendrar um roteiro que tivesse tantas reviravoltas espetaculares quanto as que marcaram a trajetória deste homem que, agora, no começo de uma tarde nublada, acaba de chegar ao prédio das Organizações Arnon de Mello, num automóvel de vidros escuros. (NETO, 2005, p. 67). 
Podemos perceber a forma como o autor do livro-reportagem atribui importância à história que virá a ser contada, desacreditando que uma história de ficção pudesse ser tão criativa a ponto de retratar acontecimentos como os que de fato, aconteceram com o ex-presidente. Entretanto, a literariedade já se faz presente no primeiro parágrafo. Normalmente, em uma reportagem jornalística, que se pretende objetiva e exclusivamente informativa, não são utilizados tantos recursos descritivos para detalhar uma cena como ocorre neste livro. Quando o autor escreve, por exemplo, sobre a "tarde nublada" e a respeito do "automóvel de vidros escuros", já não se tem mais a esperada objetividade. Estas informações, ainda que verídicas, assemelham-se à linguagem de um romance, em que o cenário dos acontecimentos, normalmente, é detalhadamente descrito. Este recurso é utilizado por diversas vezes ao longo do texto que estamos analisando. Na página 72, por exemplo, o jornalista descreve em minúcias a sala do ex-presidente, inclusive discorrendo sobre as canetas dispostas na mesa e os CDs que fazem parte do seu acervo. Outro fragmento que demonstra esta mesma reflexão é o que segue:

Que ninguém pense que o manda-chuva desfila pelo pátio soltando fogo pelas narinas. Não é assim que a banda toca hoje. Quem vê o Fernando Collor de Mello de 56 anos de idade fica tentado a perguntar: por onde anda aquela figura de andar empertigado, olhar desafiador e peito estufado, que, na presidência, encarava os outros mortais com ar de olímpica superioridade? (NETO, 2005, p. 68)

Mais uma vez, a linguagem, que inclusive utiliza metáforas ("Não é assim que a banda toca hoje"), evidencia a presença mais evidente do espaço ficcional, já que a narrativa refere-se à percepção do narrador sobre o entrevistado. Ao dar segmento ao texto, o jornalista compara a trajetória de Collor a um filme ficcional.

\begin{abstract}
A derrota nas urnas é um indício de que, aos olhos do eleitor, Collor se transformou num homem marcado pela "Síndrome de Tio Charlie" - o protagonista do filme $A$ Sombra de uma Dúvida, dirigido por Alfred Hitchcock em 1943. O gênio do suspense lançou mão de um recurso sutilíssimo para sugerir que "Tio Charlie", interpretado pelo ator Joseph Cotten, tinha um passado tenebroso: quando chega à estação, o trem que conduz o personagem projeta uma sombra sobre a família que o espera na plataforma. O trem que conduz Collor parece projetar uma sombra carregada de dúvidas sobre os eleitores. (NETO, 2005, p. 70)
\end{abstract}

Esta literatura atrelada ao real, e unida à ficcionalidade, vem para incrementar a obra, que poderia ser apenas histórica. Ricoeur afirma que os traços do imaginário "vêm enriquecer essas mediações imaginárias e [que], por isso mesmo, se dá o entrecruzamento propriamente dito da ficção e da história na refiguração do tempo" (2010, p. 317).

$\mathrm{Na}$ obra de Neto, a reconstrução dos acontecimentos, que poderia ser feita unicamente através das entrevistas - e desta maneira talvez não fosse tão atraente utiliza recursos não somente com a intenção de informar em maior medida, mas muito possivelmente, a fim de trazer elementos que, além de contribuírem para esta refiguração do tempo, trazem encanto ao texto. Este incremento na linguagem observa-se também no seguinte trecho: "O 'Escorraçado' guarda um baú de histórias. 
Vai abri-lo agora para revelar a cena que ninguém viu: o dia em que esteve a um passo de cometer suicídio - gesto que seria o último de uma interminável série de surpresas que o personagem Collor reservou para o Brasil" (NETO, 2005, p. 75).

A metáfora do "baú", a presença da fala exagerada, na referência à "interminável série" de surpresas e a referência a Collor como um personagem histórico para o país são elementos que, para além da informação, contribuem para uma leitura capaz de despertar maior interesse e curiosidade. Segundo Ricoeur, é possível que haja uma união entre arte e retórica, a fim de remeter a um fato passado. Nesse sentido, o autor salienta que uma "mesma obra pode, portanto, ser um grande livro de história e um admirável romance. $O$ incrível é que esse entrelaçamento da ficção à história não enfraquece o projeto de representância desta última, mas contribui para realizá-lo" (2010, p. 318).

Nossa proposta não consiste em discutir se o livro Dossiê Brasília - Os segredos dos presidentes é um romance, uma vez que não é desta forma que a obra é proposta. Contudo, se considerarmos a linguagem utilizada e o modo como Geneton Moraes Neto conduz a narrativa, podemos verificar os traços ficcionais, possibilitando uma leitura diferenciada. Como enfatiza Ricoeur, "pode-se ler um livro de história como um romance" (2010, p. 318). Embora a obra que estamos analisando apresente, além da narrativa escrita pelo jornalista, o esquema perguntas-respostas, podemos observar que algumas das próprias indagações trazem um certo trabalho da linguagem, típico do romance, em seu contexto. Tomemos como exemplo a pergunta "Hoje, o senhor vê um toque trágico na história de ascensão e queda - tão rápidas que o senhor viveu?" (NETO, 2005, p.78), na qual é evidente que o jornalista não se referia a uma queda física do ex-presidente; do mesmo modo, a referência à "ascensão" ao poder é uma linguagem metafórica.

Outro elemento que nos permite concluir que a obra possa ser lida como um romance são as páginas que aparecem como uma "quebra" no texto, trazendo fotografias e frases marcantes, ora do entrevistado, ora do próprio autor: "O cenário estava pronto para o suicídio: afastado do poder, Collor tranca-se na biblioteca da Casa da Dinda, liga o gravador para deixar uma mensagem" (NETO, 2005, p. 80). Fragmentos como este são capazes de movimentar o imaginário do leitor, que para além de tomar conhecimento a respeito de uma informação histórica do ex-presidente, tem a possibilidade de imaginar uma cena e recriar um acontecimento.

Wolfgang Iser (1996) afirma que o imaginário se dá de forma difusa; contudo, permite justamente projetar o inexistente, admitindo a recriação do possível a partir de outra realidade. A obra do jornalista Neto traz o real e não aquilo que inexiste; entretanto, é possível que, a partir da leitura, o receptor do texto possa reinventar aspectos históricos, aliando a forma como o autor apresenta esta história àquilo que ele mesmo é capaz de construir pela sua imaginação.

Nesse sentido, Ricoeur também destaca as possibilidades de reconstruções a partir da leitura daquilo que é histórico: "A história é quase fictícia sempre que a quase presença dos acontecimentos colocados 'diante dos olhos' do leitor por uma narrativa animada suprir, por sua intuitividade e sua vivacidade, o caráter elusivo da preteridade do passado, que os paradoxos da representância ilustram" (2010, p. 325). 
Percebemos, mais uma vez, a linha tênue entre história e literatura, partindo da ficção, que se apresenta tanto na construção da narrativa, quanto no próprio processo de leitura. É a presença da literariedade que traduz essa vivacidade no contexto da obra, conforme as percepções tanto de autor, quanto de leitor.

Como mencionamos no componente introdutório deste ensaio, para responder aos questionamentos feitos pelo jornalista, foi preciso que o entrevistado precisasse recorrer à memória do tempo em que esteve à frente da majoritária do Brasil. Como Pierre Nora raciocina, aquilo que é chamado de memória já não se constitui simplesmente de recordações, mas da própria história. "Na mistura, é a memória que dita e a história que escreve" (NORA, 1993, p. 24).

Entre as últimas perguntas destinadas ao ex-presidente Fernando Collor de Mello, um questionamento enquadra-se justamente nesse contexto. "Por que o senhor vem adiando tanto a publicação de suas memórias?" (NETO, 2010, p. 120). A indagação do jornalista Neto foi construída não somente acerca do adiamento da publicação, mas considerando a relevância histórica de uma obra a respeito da figura do ex-presidente no contexto nacional.

A partir destas análises, podemos considerar, finalmente, que embora a obra de Geneton Moraes Neto, Dossiê Brasília - Os segredos dos presidentes, seja classificada como um livro-reportagem, há a presença da literariedade e, portanto, da ficção em sua narrativa. Desde a apresentação do ex-presidente Fernando Collor de Mello objeto desta análise -, ao modo como as perguntas são conduzidas, e até mesmo às respostas do político, é possível verificar o entrecruzamento entre a realidade e a ficção.

Os fatos apresentados, históricos, por remeterem ao período no qual um presidente esteve à frente do Brasil, representam também um resgate da memória do próprio líder, que rememorou sua trajetória e a contou para o jornalista. Por outro lado, esta história vem acompanhada por metáforas, interpretações, imagens produzidas e inclusive, pelo incremento na escrita, que é construída no sentido de persuadir o leitor a verificar as próximas páginas da obra. Esta forma como o texto se edifica permite que a narrativa seja lida como um romance, ainda que não o seja. Mesmo que grande parte da obra permaneça configurada no formato perguntaresposta, isso não impede o escritor de dispor de textos introdutórios, destacar frases que considera mais pertinentes e, ainda, orientar os questionamentos para que tenham uma sequência lógica de leitura. Sendo assim, a aproximação entre a realidade e ficção, história e literatura, fica mais uma vez evidenciada através da obra Dossiê Brasília - Os segredos dos presidentes.

\section{REFERÊNCIAS}

FONTANA, Mônica. Os limites entre fato e ficção: jornalismo literário em perspectiva.

Anais do Evento PG Letras 30 Anos. V. I (1): 325-333. Disponível em:

<http://www.pgletras.com.br/Anais-30-

Anos/Docs/Artigos/3.\%20Pesq\%20em\%20andamento\%20Literatura/3.6_Monica_Font ana.pdf>. Acesso em: 15 abr. 2013. 
ISER, Wolfgang. O fictício e o imaginário: perspectivas de uma antropologia literária. Rio de Janeiro: EdUERJ, 1996.

LAGE, Nilson. A reportagem: teoria e técnica da entrevista e pesquisa jornalística. Rio de Janeiro: Record, 2001.

LIMA, Edvaldo Pereira. Páginas ampliadas: o livro-reportagem como extensão do jornalismo. Campinas: Unicamp, 1995.

NETO, Geneton Moraes. Dossiê Brasília - os segredos dos presidentes. São Paulo: Globo, 2005.

NOBLAT, Ricardo. Sobre a imparcialidade do jornalista. Disponível em: <http://oglobo.globo.com/pais/noblat/posts/2012/03/20/sobre-imparcialidade-dojornalista-8-anos-de-blog-436592.asp>. Acesso 13 abril 2013.

NORA, Pierre. Entre memória e história. In: Projeto História. Trad. de Yara Aun Khoury. São Paulo, 1993.

RICOEUR, Paul. O entrecruzamento da história e da ficção. In: Tempo e

Narrativa. Trad. de Claudia Berlinder. São Paulo: Wmfmartinsfontes, 2010.

Title: History and fiction in Geneton Moraes Neto's reportage book Dossiê Brasília - os segredos dos presidentes

Abstract: This work presents an analysis of Geneton Moraes Neto's book Dossiê Brasília - Os segredos dos presidentes, which brings information in the questionanswer format, providing also additional texts to introduce politicians, so as to bring to light the facts behind the scenes of power history in Brazil. The objective of the study is to verify the existence of the intersection between reality and fiction in the work; this study relies on various scholars, but, especially, on Paul Ricoeur. This study takes as object the section dedicated to the introductiona and interview with the expresident Fernando Collor de Mello, who was the target of many controversies that involved his administration and removal from power. The analysis reveals the presence of literature in a journalistic work, corroborating the idea that history and fiction may coexist in a same work.

Keywords: Reality. Fiction. Reportage-book. Literature. History. Geneton Moraes Neto

Recebido em: 08/09/2013. Aceito em 30/11/2013 